COMUNICAÇÃO CIENTÍFICA

\title{
DETECÇÃO E ISOLAMENTO DE ROTAVÍRUS CAPRINO DO GRUPO A
}

\section{M.G. Buzinaro, S.I. Samara, A.A.B. Carvalho, J.V. Pontes*, R. Salles**, D.G. Silva**}

Universidade Estadual Paulista, Faculdade de Ciências Agrárias e Veterinárias, Departamento de Medicina Veterinária Preventiva e Reprodução Animal, Via de Acesso Prof. Paulo Donato Castellane s/nº, CEP 14884900, Jaboticabal, SP, Brasil. E-mail: glorinha@fcav.unesp.br

\section{RESUMO}

Rotavírus é a principal causa de diarreia em animais jovens de várias espécies. Os rotavirus estão classificados na família Reoviridae e contêm um genoma formado por 11 segmentos de RNA de cadeia dupla, envolvidos em três camadas proteicas. Neste estudo, foi detectado rotavírus pela eletroforese em gel de poliacrilamida (PAGE) em amostras de fezes de caprinos, com 80 dias de idade, durante surto de diarreia em um rebanho leiteiro. O perfil eletroforético das amostras, denominadas cap01/2007 e cap02/2007, foi caracterizado no PAGE como sendo de rotavírus do grupo A. Para o isolamento viral, suspensão fecal a $20 \%$ em tampão tris $0,1 \mathrm{M}$ pH 7,3 foi filtrada e tratada com tripsina cristalina na concentração de $5 \mathrm{mg} / \mathrm{mL}$. A amostra caprina cap01/2007 foi inoculada em cultura de células MA104 (Rim de Macaco Rhesus). Foram testados dois tratamentos (T1 e T2): após adsorção (estufa $37^{\circ} \mathrm{C}$ por uma hora) adicionou-se meio de manutenção (DulbeccoMEM) sem tripsina, mantendo o inóculo (T1). No tratamento 2 (T2), foi realizado o mesmo procedimento anterior, porém o inóculo foi dispensado. O efeito citopático foi observado na primeira passagem para ambos os tratamentos (T1 e T2) com 48 horas de inoculação e o isolamento viral foi confirmado no PAGE. O perfil de migração manteve-se inalterado após três passagens sucessivas. Este é o primeiro relato de isolamento de rotavírus em caprinos no Brasil.

PALAVRAS-CHAVE: Rotavírus, caprino, isolamento, célula MA-104.

\section{ABSTRACT}

DETECTION AND ISOLATION OF GROUP A CAPRINE ROTAVIRUS. Rotavirus is the main cause of diarrhea in young animals of several species. They are classified as a genus within the virus family Reoviridae. Rotaviruses have a segmented genome made up of a double-stranded RNA. It is divided into 11 segments and surrounded by a triple protein capsid. In this study, Rotavirus was detected by polyacrylamide gel electrophoresis (PAGE) in feces samples of 80-day-old goats during a diarrhea outbreak in a milk-producing herd. The sample's electrophoretic pattern, called cap01/2007, was characterized as Group A rotavirus. A 20\% fecal suspension in buffer TRIS 0.1M pH 7.3 was filtered and treated with crystalline trypsin in a $5 \mathrm{mg} / \mathrm{mL}$ concentration for viral isolation. Caprine sample Cap01/2007 was inoculated in MA-104 cells (Rhesus's kidneys) with a 48-hour growth. Two treatments (T1 and T2) were tested. In T1, maintenance medium without trypsin was added (Dulbecco-MEM) after adsorption (buffer at $37^{\circ} \mathrm{C}$ for $1 \mathrm{~h}$ ) the inoculum was maintained. In treatment $\mathrm{T} 2$, the previous procedure without the inoculum was performed. Cytopathic effect was observed in the first passage for both treatments (T1 and T2) with 48h inoculation, and viral isolation was then confirmed by PAGE. Migration design remained unchanged after 3 successive passages. This is the first report of isolation of caprine rotavirus in Brazil.

KEY WORDS: Rotavirus, goats, diarrhea, isolation, MA-104 cells.

As doenças entéricas constituem um dos principais problemas sanitários que afetam principalmente animais jovens de várias espécies, resultando em grandes perdas econômicas em virtude da morbidade e mortalidade. Dentre os vários enteropatógenos envolvidos nesta síndrome destacam-se os rotavírus
(SNODGRASs et al., 1986). Pertencente à família Reoviridae, os rotavírus possuem um genoma segmentado formado por RNA de cadeia dupla, dividido em 11 segmentos e rodeado por um capsídeo triplo proteico (Estes; COHEN, 1989). As proteínas externas do capsídeo, (VP4 e VP7), estão relacionadas às funções

*Bolsista de Iniciação Científica-Fapesp - FCAV/Unesp.

**Doutoranda em Medicina Veterinária - FCAV/Unesp. 
importantes como tropismo, ligação de receptor celular e penetração do vírus nas células (TANIGUCHI et al., 1993). Ouso de enzimas proteolíticas, como a tripsina, permitiu o isolamento de várias estirpes de rotavírus. Omecanismo está relacionado à clivagem da proteína VP4 (88.000 daltons) em dois polipeptídeos menores, VP5 de 67.000 daltons e VP8* de 20.000 daltons, aumentando a infectividade viral (ARIAS et al., 1996). Por meio desse procedimento, rotavírus de diferentes espécies animaisforam isolados:canina(HosHINOetal., 1982); equina(IMAGAWAetal., 1984); leporina (CASTRUCCI et al., 1985); ovina (MAKABE et al., 1985); suína (FERRARI et al., 1986) e bovina (HuANG et al., 1992). Embora de difícil isolamento, estirpes de rotavírus adaptadas em cultivo celular têm contribuído com estudos in vivo e in vitro para uma melhor compreensão da cadeia de transmissão e ciclo de replicação do agente. Em caprinos há poucos trabalhos descrevendo a detecção e o isolamento de rotavírus em cultura de células (Costa Mendes et al., 1994; Pratelli el al., 1999; Lee et al.,2003). Esteestudo descrevea detecção derotavírus durante surto de diarreia em caprinos e o isolamento viral em cultura de células da linhagem MA-104 (rim de macaco Rhesus).

Amostras de fezes de dois cabritos da raçaSaanen, com 80 dias de idade, foram colhidas durante surto de diarreia no ano de 2007, de um rebanho leiteiro do Município de Jaboticabal, Estado de São Paulo, Brasil. As amostras foram colhidas diretamente da ampola retal, acondicionadas em sacos plásticos e mantidas a temperatura de $-20^{\circ}$ C até a análise.

As amostras defezes foram analisadas pela técnica de eletroforese em gel de poliacrilamida (PAGE). Foram preparadas suspensões de fezes a $20 \%$ em tampão tris/cálcio (Tris/ $\mathrm{HCl} 0,1 \mathrm{M} ; \mathrm{CaCl}_{2} 1,5 \mathrm{mM}$ $\mathrm{pH} 7,3$ ) e o sobrenadante testado para detecção de rotavírus. O RNA foi extraído da suspensão fecal com fenol/clorofórmio (Pereira et al.,1983), analisado num sistema de tampão descontínuo de LAEMmLI (1970) e aplicado em gel de poliacrilamida a 7,5\%, conduzido a $20 \mathrm{~mA}$ durante 2 horas. Para visualizar as bandas gel de poliacrilamida foi corado com nitrato de prata (HERRING et al. (1982).

Foi utilizada como padrão a estirpe de rotavírus bovino NCDV (Nebraska Calf Diarrhoea Vírus).

Culturas de células da linhagem MA-104 foram cultivadas em garrafas de poliestireno de $25 \mathrm{~cm}^{2}$, utilizando meio Dulbecco - Minimal Essential Medium(D-MEM) suplementado com $10 \%$ de soro fetal bovino(SFB) e2,2 mg de NaHCO3. Asculturas foram inoculadas após 48 horas de crescimento.

Suspensão fecal à 20\% em tampão tris/ cálcio 0,1 $\mathrm{M} \mathrm{pH} \mathrm{7,3} \mathrm{foi} \mathrm{centrifugada} \mathrm{a} 2.000 \mathrm{~g}$ por 30 minutos e filtrada em membranas filtrantes Milex-Millipore de $0,22 \mu \mathrm{m}$ de porosidade. Após filtração, $0,5 \mathrm{~mL}$ da suspensão fecal foi misturada com $30 \mu \mathrm{L}$ de Virus
ActivationSolution(V.A.S.) que contém tripsina cristalina na proporção de $5 \mathrm{mg} / \mathrm{mL}$ de meio (D-MEM), para clivagem da VP4 em VP5 e VP8, e incubada em banho-maria a $37^{\circ} \mathrm{C}$ por $30 \mathrm{~min}$.

A monocamada de células contidas no interior das garrafas de cultivo foi lavada três vezes com PBS 0,1M, pH 7,2, para remoção de resíduos de SFB e do meio de cultivo, e o inóculo foi transferido para a monocamada. A adsorção foi realizada por 60 minutos em estufa a $37^{\circ} \mathrm{C}$, homogeneizando a cada $15 \mathrm{~min}$. Foram testados dois tratamentos: No tratamento 1 adicionou-se $4 \mathrm{~mL}$ de meio de manutenção (D-MEM) sem tripsina, mantendo o inóculo. No tratamento 2 foi realizado o mesmo procedimento anterior, porém o inóculo foi dispensado. As garrafas foram incubadas em estufa a $37^{\circ}$ Ceas monocamadas foram observadas diariamente até 96 horas após inoculação para observação do efeito citopático. As garrafas foram congeladas e descongeladas três vezes e, após centrifugação a 1.080 × g $40 \mu \mathrm{L}$ do sobrenadante de cultivo celular, foram adicionados a $40 \mu \mathrm{L}$ de dissociador de RNA (sódio dodecil sulfato $10 \% ; 12,5 \%$ Tris/ $\mathrm{HCl}$ 0,5M pH 6,8; 5\% 2-mercapto-etanol; ureia $3 \mathrm{~g} ; 0,5 \%$ azul de bromofenol). A mistura foi incubada em banho-maria a $37^{\circ} \mathrm{C}$ por 30 minutos. Foram feitas cinco passagens sucessivas e a comprovação do isolamento foi realizado pela técnica de PAGE.

Rotavírus foi detectado por PAGE nas fezes de dois cabritos, com 80 dias de idade, de um rebanho leiteiro, apresentando diarreia, anorexia e desidratação. A análise do perfil de migração dos segmentos do RNA viral revelou, em ambas as amostras (cap01/2007 e cap02/2007), um padrão compatível com o perfil de migração de rotavírus do grupo A, quando comparados com a estirpe NCDV de rotavírus bovino (Fig. 1). A amostra caprina de rotavírus cap01/2007 foi isolada em células MA104 na primeira passagem. O efeito citopático foi observado às 48 horas de incubação com células alongadas e posterior descolamento total do tapete celular às 96 horas de inoculação. A amostra foi inoculada seguindo-se cinco passagens sucessivas e o isolamento foi confirmado pela observação do efeito citopático e a presença de segmentos do RNA no PAGE. O perfil de migração no PAGE da mostra cap01/2007 cultivada em células MA-104 foi comparável ao da amostra original (Fig. 1). A quantidade de fezes da amostra cap02/2007 impossibilitou o teste de isolamento em células por fornecer material insuficiente para o preparo da suspensão fecal.

Rotavírus do grupo A é considerado um dos principais agentes de diarreia em animais jovens de várias espécies, contudo, em caprinos há poucos relatos sobre a detecção deste agente, bem como sobre as características genotípicas e de adaptação 
em células (Costa Mendes et al.,1994; Pratelli et al., 1999; LeE et al., 2003). Neste estudo, foi detectado rotavírus por PAGE nas fezes de dois cabritos com diarreia de um rebanho leiteiro da raça Saanen do Município de Jaboticabal, Estado de São Paulo. Um dos animais veio a óbito no terceiro dia de evolução do quadro. As amostras de rotavírus, cap01/2007 e cap02/2007, apresentaram o mesmo perfil eletroforético, característico de rotavírus do grupo A (Fig. 1). O sucesso do isolamento de rotavírus caprino em células da linhagem MA-104 pode ser atribuído ao pré-tratamento da amostra com tripsina, conforme também relatado por CosTA MENDES et al. (1994). Em virtude da pequena quantidade de fezes somente foram testados dois tratamentos (T1 e T2) que consistiram em: tratamento da suspensão de fezes com tripsina e sem dispensar o inóculo após a adsorção (T1) e tratamento da suspensão com tripsina dispensando o inóculo após a adsorção (T2). Em ambos os tratamentos foi detectado efeito citopático às 24 horas de incubação e confirmada a presença de RNA de rotavírus no PAGE na primeira passagem. Outros autores, no entanto, relataram dificuldades no isolamento de rotavírus. Gouveia et al. (1991) descreveram o isolamento de cinco amostras $(4,8 \%)$ de rotavírus de suínos de um total de 103 estudadas, enquanto HuANG et al. (1992) relataram que de 20 amostras de rotavírus bovinos apenas duas (10\%) foram isoladas em células MA-104.

Existe também uma grande variação na concentração de tripsina tanto no inóculo quanto no meio de manutenção. Hoshino et al. (1982) isolaram amostra de rotavírus canina utilizando $2,5 \mu \mathrm{g} / \mathrm{mL}$ de tripsina no inóculo. Kutsuzawa et al. (1982) isolaram amostras humanas utilizando $10 \mu \mathrm{g}$ e $0,5 \mu \mathrm{g} /$ $\mathrm{mL}$ de tripsina no inóculo e meio de manutenção, respectivamente. IMAGAWA et al. (1984) isolaram rotavírus de equinos utilizando concentrações de tripsina de $1 \mu \mathrm{g} / \mathrm{mL}$ no inóculo e $20 \mu \mathrm{g} / \mathrm{mL}$ no meio de manutenção. CASTRUCCI et al. (1985) isolaram rotavírus de coelho usando $1.000 \mu \mathrm{g} / \mathrm{mL}$ no inóculo e $5 \mu \mathrm{g} / \mathrm{mL}$ no meio de manutenção. LeE et al. (2003) isolaram amostra caprina de rotavírus utilizando 0,5 $\mu \mathrm{g} / \mathrm{mL}$ de tripsina. RodRIGUEZ et al. (2004) isolaram amostras de suínos e bovinos usando $5 \mu \mathrm{g} / \mathrm{mL}$ no meio de manutenção, mantendo o inóculo. No presente trabalho somente foi utilizado tripsina no preparo do inóculo $(5 \mathrm{mg} / \mathrm{mL})$. Embora de difícil isolamento, estirpes de rotavírus adaptadas em cultivo celular têm contribuído com estudos in vivo e in vitro para uma melhor compreensão da cadeia de transmissão e ciclo de replicação do agente. Estudos anteriores não foram conclusivos quanto a associação de rotavírus com sinais de diarreia em caprinos, sendo necessário outros trabalhos para investigar a associação de rotavírus com casos clínicos de diarreia.

\section{AGRADECIMENTOS}

Os autores agradecem à FAPESP pelo apoio financeiro. segmentos

1

$2,3,4$

5

6

$7,8,9$

10

11

123

4

5

6

7

8

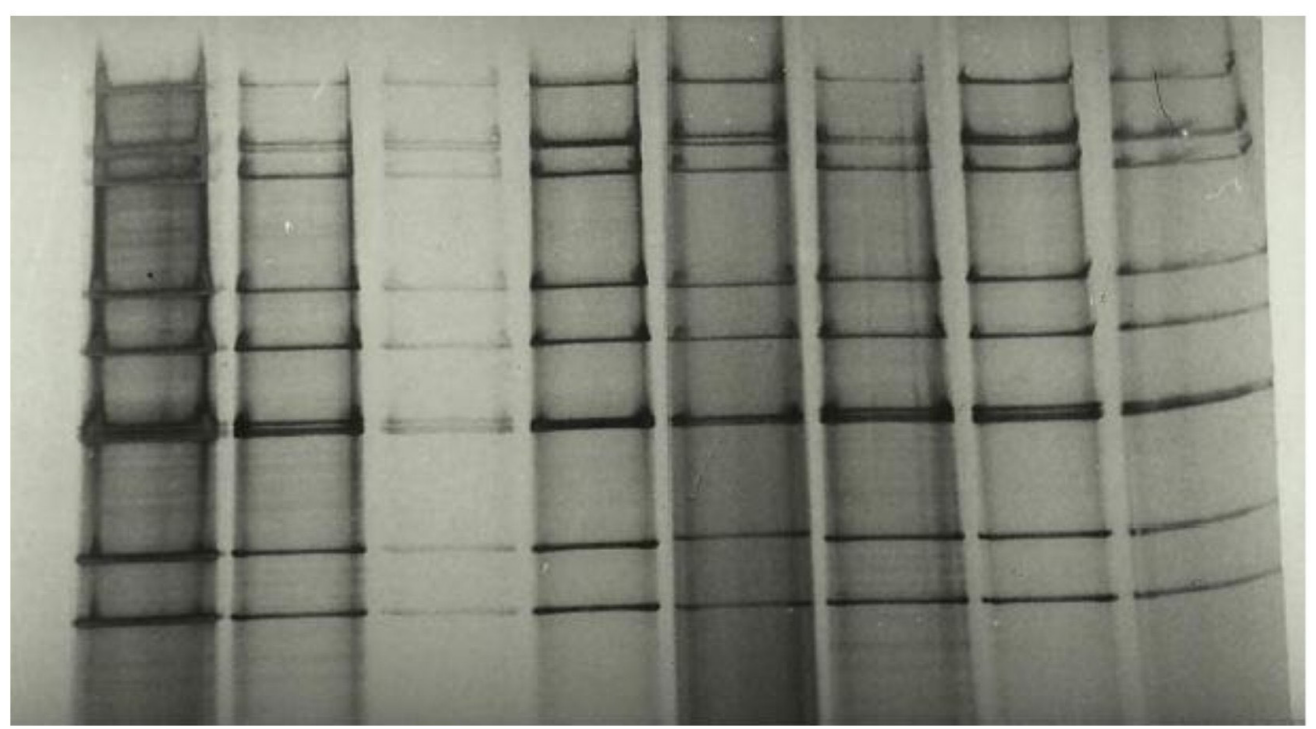

Fig. 1. Perfil eletroforético do genoma de rotavírus da amostra Cap 01/2007 detectada por PAGE nas fezes de caprinos (2) e isoladas em cultura de células MA-104 (3). 1. Estirpe de rotavírus padrão NCDV (nebraska calf diarrhoea virus); 4 a 8 estirpes de rotavírus de campo detectadas em bovinos. Números à esquerda indicam os segmentos genômicos. 


\section{REFERÊNCIAS}

ARIAS, C.F.; ROMERO, P.; ALVAREZ, V.; LOPÉZ, S. Trypsin activation pathway of rotavirus infectivity. Journal of Virology, v.70, n.9, p.5832-5839, 1996.

CASTRUCCI, G.; FERRARI, M.; FRIGERI, F.; CILLI, V.; PERUCCA, L.; DONELLI, G. Isolation and characterization of cytopathic strains of rotavirus from rabbits. Archives of Virology, n.83, p.99-104, 1985.

COSTA MENDES, V.M.; BEER, M.C.; GOOSEN, G.H.; STEELE, A.D. Isolation and preliminary characterization of a caprine rotavirus. Onderstepoort Journal of Veterinary Research, n.61, p.291-294, 1994.

ESTES, M.K.; COHEN, J. Rotavirus gene structure and function. Microbiological Reviews, n.53, p.410-449, 1989.

FERRARI, M.; GUALANDI, G.L.; GELMETTI, D. Isolation of cytopathic strains of rotavirus from pigs. Microbiologica, v.9, p.287-295, 1986.

GOUVEIA, A.M.; NOZAWA, C.M.; ARAÚJO, H. Cell culture propagation of rotavirus from feces of diarreic piglets. Revista de Microbiologia, v.22, p.108-111, 1991.

HERRING, A.J.; INGLIS, N.F.; OJEH, C.K.; SNODGRASS, D.R.; MENZIES, J.D. Rapid diagnosis of rotavirus infection by direct detection of viral nucleic acid in silver - stained polyacrylamide gels. Journal of Clinical Microbiology, v.16, n.3, p.473-77, 1982.

HOSHINO, Y., WATT, R.G., SCOTT, F.W., APPEL, M.J. Isolation and characterization of canine rotavirus. Archives of Virology, v.72, p. 113-25, 1982.

HUANG, J.A.; NAGESHA, H.S.; SNODGRASS, D.R.; HOLMES, I.H. Molecular and serological analyses of two rotavirus (B11 and B60) caising calf scours in Australia. Journal of Clinical Microbiology, v.30, p.85-92, 1992.

IMAGAWA, H.; WADA, R.; HIRASAWA, K.; ODA, T. Isolation of equine rotavirus in cell culture from foals with diarrhea. Journal of Veterinary Science. v.46, n.1, p.1-9, 1984.

KUTSUZAWA, T.; KONNO, T.; SUZUKI, H.; KAPIKIAN, A.Z.; EBINA, T.; ISHIDA, N. Isolation of human rotavirus subgroup 1 and 2 cell culture. Journal of Clinical Microbiology, v.16, n.4, p.727-730, 1982.

LAEMMLI, U.K. Cleavage of structural proteins during the assembly of the head of bacteriophage T4. Nature, n.227, p.680-685, 1970.

LEE, J.B.; YOUN, S.J.; NAKAGOMI, T.; PARK, S.Y.; KIM, T.J.; SONG, C.S.; JANG, H.K.; KIM, B.S.; NAKAGOMI, O. Isolation, serologic and molecular characterization of the first G3 caprine rotavirus. Archives of Virology, v.148, p.643-657, 2003.

MAKABE, T.; KOMANIWA, H.; KISHI, T.; YATAYA, K.; IMAGAWA, H.; SATO, K.; INABA, Y. Isolation of ovine rotavirus in cell culture. Archives of Virology, v.83, p.123-127, 1985.

PEREIRA, H.G.; AZEREDO, R.S.; LEITE, J.P.G.; CANDEIAS, J.A.N.; RÁCZ, M.L.; LINHARES, A.C.; GABBAY, Y.B.; TRABULSI, J.R.. Eletrophoretic study of the genome of human rotaviruses from Rio de Janeiro, São Paulo e Pará, Brasil. Journal of Hygiene, v.80, p.117-125, 1983.

PRATELLI, A., MARTELLA, V., TEMPESTA, M., BUONAVOGLIA, C. Characterization by polymerase chain reaction of ruminant rotaviruses isolated in Italy. New Microbiology, v.22, n.2, p.105-109, 1999.

RODRIGUEZ, C.A.R.; BRANDÃO, P.E.; FERREIRA, F.; GREGORI, F.; BUZINARO, M.G.; JEREZ, J.A. Improved animal rotavirus isolation in MA104 cells using different trypsin concentrations. Arquivos do Instituto Biológico, São Paulo, v.71, n.4, p.437-441, 2004.

SNODGRASS, D.R.; TERZOLO, H.R.; SHERWOOD, D.; CAMBELL, I.; MENZIES, J.D. Aetiology of diarrhoea in young calves. Veterinary Record, v.12, n.119, p.31-34, 1986.

TANIGUCHI, K.; URASAWA, T.; URASAWA, S. Independent segregation of the VP4 and VP7 genes in bovine rotavirus as confirmed VP4 sequence analysis of G8 and G10 rotavirus strains. Journal of General Virology, v.74, p.1215-1221, 1993.

Recebido em $1 / 10 / 09$

Aceito em 13/4/11 